\title{
Evaluación del efecto antibacteriano in vitro del extracto de Zingiber officinale en Escherichia coli y Salmonella typhimurium en cerdos
}

\section{Antibacterial effect in vitro of Zingiber officinale extract on Escherichia coli and Salmonella typhimurium in pigs}

\author{
Gleysi Acosta López ${ }^{1}$, Reiner Pedro Gabriel Reátegui Inga², Manuel Emilio Reátegui Inga ${ }^{3}$
}

\section{RESUMEN}

Con el objetivo de evaluar el efecto del extracto de kion (Zingiber officinale) en el control in vitro de Escherichia coli y Salmonella typhimurium, se recolectaron muestras de heces de cerdos entre los 30 y 90 días de edad que presentaron síntomas de tener enfermedades causadas por E. Coli y S. typhimurium. El aislamiento y cultivo de cepas bacterianas se realizaron en el Laboratorio de Enfermedades Infecciosas y Parasitarias de Animales Domésticos de la Universidad Nacional Toribio Rodríguez de Mendoza de Amazonas (UNTRM). El análisis de varianza y la comparación de medias de Tukey $(\mathrm{p}=0.05)$ evidenciaron que el extracto de kion a concentraciones de $0 \%, 10 \%, 20 \%, 30 \%, 40 \%, 50 \%$ y $60 \%$ no muestran ningún efecto antibacteriano frente a Escherichia coli y Salmonellatyphimurium.

Palabras clave: Extracto de kion, efecto antibacteriano

\begin{abstract}
With the aim of evaluating the effect of kion extract (Zingiber officinale) on the in vitro control of Escherichia coli and Salmonella typhimurium, samples of feces from pigs between 30 and 90 days of age that presented symptoms of having diseases caused by E. Coli and S. typhimurium. The isolation and culture of bacterial strains were carried out in the Laboratory of Infectious and Parasitic Diseases of Domestic Animals of the Universidad Nacional Toribio Rodríguez de Mendoza de Amazonas (UNTRM). The analysis of variance and the comparison of Tukey means $(\mathrm{p}=0.05)$ showed that the kion extract at concentrations of $0 \%, 10 \%, 20 \%, 30 \%, 40 \%, 50 \%$ and $60 \%$ do not show any antibacterial effect against Escherichia coli and Salmonella typhimurium.
\end{abstract}

Keywords: Kion extract, antibacterial effect

\footnotetext{
${ }^{1}$ Bachiller de la Facultad de Ingeniería Zootecnista, Agronegocios y Biotecnología. Universidad Nacional Toribio Rodríguez de Mendoza de Amazonas.

${ }^{2}$ Docente de la Facultad de Ingeniería Zootecnista, Agronegocios y Biotecnología. Universidad Nacional Toribio Rodríguez de Mendoza de Amazonas. Maestro en Ciencias. Correo electrónico: reiner.reategui@untrm.edu.pe

${ }^{3}$ Docente de la Facultad de Ingeniería Forestal y Ambiental. Universidad Nacional de Jaén. Maestro en Ciencias. Correo electrónico: manuel.reategui@unj.edu.pe
} 


\section{INTRODUCCIÓN}

Las enfermedades transmitidas por alimentos conocidas como la ingestión de un alimento contaminado que contiene algún microorganismo son las que generan diferentes enfermedades como Colibacilosis, Escherichia coli, Triquinosis y Salmonelosis causando grandes pérdidas a nivel porcicultor Fierro et al. (2011).

Flores (2014) La salmonelosis es una enfermedad causada por serotipos de Salmonella ssp, la presencia de ésta bacteria en porcinos se manifiesta como septicemia o enterocolitis, provocando diarreas de color amarillo y con problemas respiratorios y nerviosos.

La colibacilosis es una enfermedad causada por Escherichia coli enterotoxigénicos (ECET), son muy frecuentes en los animales domésticos llegando a afectar frecuentemente a los animales que se encuentran a pocos días de nacido y a los recién destetados, ocasionando grandes pérdidas económicas a nivel mundial, Blanco (Lazo, 2010). Así mismo VuKhac y Col. (2010) nos reafirma que las consecuencias ocasionadas por la diarrea pos destete en cerdos, síntomas característicos de estas bacterias son el principal problema infeccioso de las granjas a gran escala.

Bustos y Segura (2005) explican que la Salmonella $s s p$. tiene como reservorio principal el intestino de los animales, teniendo como ruta de transmisión más común la vía fecal/oral, además forma parte una más de las causas de contaminación en los alimentos de origen animal debido al riesgo que presenta para la salud humana sobre todo por la presencia de la enfermedad diarreica aguda.

Por otro lado las plantas medicinales son un recurso de gran importancia como ingrediente alternativo para dar solución y mejoras en la salud, así nos describen Ñahuis y Enciso (2018), que dichas plantas están ofreciendo una gran fuente de sustancias activas que actúan frente a muchas bacterias; por ello, el interés en buscar y encontrar distintas especies vegetales que tengan efectos benéficos en diversas especies vivas ha ido en incremento.

El jengibre es una planta considerada medicinal cuyos componentes son 4-7,5\% de oleorresina, en la que destacan el aceite esencial y las sustancias picantes, también se encuentran los sesquiterpenos, como $\alpha$-zingibereno, ar-curcumeno, $\beta$-bisaboleno, $\beta$ bisabolona, (EE)- $\alpha$-farneseno y $\beta$-sesquifelandreno, y monoterpenos, como alcanfor, $ß$-felendreno, geranial, neral y linalol., otros componentes de importancia son el almidón cuya cantidad es aproximadamente un 50\%, diterpenos, ácido 6gingesulfónico y monoacil digalactosil gliceroles, esto datos fueron reportados por Cañigueral (2014).

Ñahuis y Enciso (2018) afirman que Zingiber officinale "kion" actúa como agente antibacteriano, para comprobar esta información evaluaron diferentes concentraciones de extracto etanólico de éste producto $(25 \%, 50 \%$ y $100 \%)$ en bacterias, obteniendo un crecimiento de halo de inhibición de $10 \mathrm{~mm}, 6 \mathrm{~mm}$ y $6 \mathrm{~mm}$ respectivamente, llegando a la conclusión de que el jengibre a concentración del $25 \%$ presenta efecto antibacteriano en cepas de Escherichia coli.

Rengifo (2018) realizó una investigación en la que evaluó los efectos del aceite esencial de Zingiber officinale roscoe "jengibre en la que encontró que las concentraciones del aceite a niveles de $25 \%$ y $50 \%$ no fueron efectivos en cuanto a lo que esperaba, mostrando mínimo efecto bactericida sobre Escherichia coli ATCC 25922, con halos de inhibición de 13,6 mm y 4,9 mm respectivamente.

La finalidad de realizar la investigación en Escherichia coli y Salmonella typhimurium en cerdos es la de proporcionar información a porcicultores y población interesada para brindar soluciones, erradicar o prevenir las diferentes enfermedades causadas por éstas bacterias.

Así mismo otro indicador fue la existencia de investigaciones insuficientes sobre la utilización del extracto de kion (Zingiber officinale) como producto antibacteriano frente a la Escherichia coli y Salmonella typhimurium en la producción porcina, por otro lado se consideró la accesibilidad de los porcicultores al producto del Zingiber officinale "kion", cuyo producto se puede obtener con gran facilidad en los diversos mercados de la ciudad.

\section{MATERIAL Y MÉTODOS}

\section{Ubicación}

El trabajo de investigación se desarrolló en el Laboratorio de Enfermedades Infecciosas y Parasitarias de Animales Domésticos de la Universidad Nacional Toribio Rodríguez de Mendoza de Amazonas, la cual se encuentra en la provincia y distrito de Chachapoyas, cuya institución se ubica a $6^{\circ} 13^{\prime} 57^{\prime \prime}$ sur y $77^{\circ} 51^{\prime} 11^{\prime \prime}$ norte a una altitud de $2334 \mathrm{msnm}$, a una temperatura anual promedio de $17^{\circ} \mathrm{C}$, humedad relativa de $74 \%$ y una precipitación anual de $811 \mathrm{~mm}$.

\section{Selección de la muestra}

- Identificación de cerdos que presentaron síntomas de la presencia de salmonelosis y colibacilosis en la granja.

- Seguimiento de animales identificados, al momento de observar la defecación de los cerdos, con la ayuda de una espátula estéril se procedió a recoger las heces directamente del recto del cerdo, y luego se colocó en 6 envases de vidrio estériles, ocupando $250 \mathrm{~g}$ de 
heces aproximadamente en cada envase.

- Luego se transportó a laboratorio (lugar de evaluación) a temperatura ambiente.

\section{Métodos de recolección de datos}

\section{a. Identificación de bacterias a evaluar}

Con la finalidad de aumentar el número de bacterias de una cierta cantidad de muestras de heces, se realizó un enriquecimiento de las muestras recolectadas en agua peptonada o caldo peptonado homogeneizando adecuadamente, las cuales se llevó a incubar en una estufa por 18 a 24 horas a una temperatura de $37^{\circ} \mathrm{C}$.

Luego esas muestras enriquecidas se sembraron en agares MacConkey (MC) y Salmonella Shiguella (SS) en forma de zigzag o conocido por el método de estrías, para obtener colonias de bacterias, se incubó una temperatura de $37^{\circ} \mathrm{C}$ por 18 a 24 horas, logrando obtener diferentes familias de bacterias en el agar MC y a la bacteria en evaluación Salmonella typhimurium en el agar SS.

Para obtener la siguiente bacteria Escherichia coli se efectuó una siembra de las colonias de bacterias formadas en el agar MC en un medio específico para ésta bacteria, el agar EMB realizando la siembra en zigzag, finalmente se llevó a incubar las placas con agar EMB sembradas en una estufa a $37^{\circ} \mathrm{C}$ de temperatura por 18 a 24 horas, de la cual de identificó a la bacteria Escherichia coli mostrándose de un color verde brillante característico de ésta bacteria.

\section{b. Identificación bioquímica de bacterias a evaluar}

Se realizó las pruebas bioquímicas en medios diferenciales como: SIM, Citrato de SIMMONS, LIA Y TSI para descartar el tipo de bacterias obtenidas en los cultivos, obteniendo una lectura con los siguientes resultados:

\section{Para Escherichia coli:}

- Reacción bioquímica en SIM: H2S (+) e Indol (+)

- Reacción bioquímica en SIMMONS: Citrato (-)

- Reacción bioquímica en LIA: Lisina descarboxilasa (-) y H2S (-)

- Reacción bioquímica en TSI: Lactosa $(+)$, Sacarosa $(+)$, Glucosa $(+)$ y H2S $(+)$

\section{Para Salmonella typhimurium:}

- Reacción bioquímica en SIM: H2S (-) e Indol (-)

- Reacción bioquímica en SIMMONS: Citrato (-)

- Reacción bioquímica en LIA: Lisina descarboxilasa $(+)$ y $\mathrm{H} 2 \mathrm{~S}(+)$

- Reacción bioquímica en TSI: Lactosa (+), Sacarosa

\section{$(-)$, Glucosa (-) y H2S (+)}

Es preciso afirmar que ambos resultados pertenecen a cada una de las bacterias en estudio.

\section{c. Identificación de bacterias en tinción Gram}

Para determinar la pureza de los cultivos y para identificación respectiva microscópicamente de las bacterias en investigación se realizó la prueba de tinción o coloración Gram, para ello con los procesos descritos por Torres, (1996) en su manual práctico de bacteriología médica se procedió a brindar coloración a las bacterias de los cultivos obtenidos con los reactivos cristal violeta, mordiente o lugol, decolorante Gram y safranina para finalmente llevar al microscopio donde se identificó a las Escherichia coli y Salmonella typhimurium.

\section{d. Obtención de discos de sensibilidad}

Con la ayuda de una perforadora de escritorio se tomó un papel filtro y se realizó los cortes circulares de 6 mm de diámetro, luego se colocó en un vaso de precipitación y se llevó a esterilizar en incubadora a $150{ }^{\circ} \mathrm{C}$ por un tiempo de 1 hora, éstos discos de papel filtro nos permitió identificar el resultado del crecimiento de halo de inhibición.

\section{e. Preparación de tratamientos}

Se utilizó como insumos principales el extracto de kion (EK) y agua destilada esterilizada.

La preparación de los tratamientos se realizó con las siguientes proporciones:

- T0 (0\% EK): $25 \mathrm{ml}$ de agua destilada

- T1 (10\% EK): 22,5 ml de agua destilada $+2,5 \mathrm{ml} \mathrm{de}$ extracto de kion

- T2 (20\% EK): $20 \mathrm{ml}$ de agua destilada $+5 \mathrm{ml} \mathrm{de}$ extracto de kion

- T3 (30\% EK): 17,5 $\mathrm{ml}$ de agua destilada $+7,5 \mathrm{ml} \mathrm{de}$ extracto de kion

- T4 (40\% EK): $15 \mathrm{ml}$ de agua destilada $+10 \mathrm{ml} \mathrm{de}$ extracto de kion

- T5 (50\% EK): 12,5 $\mathrm{ml}$ de agua destilada $+12,5 \mathrm{ml} \mathrm{de}$ extracto de kion

- T6 (60\% EK): $10 \mathrm{ml}$ de agua destilada $+15 \mathrm{ml} \mathrm{de}$ extracto de kion

Ambos insumos colocados adecuadamente con cada concentración correspondiente en cada tratamiento, se procede a homogeneizar a través de movimientos circulares suaves.

\section{f. Evaluación del efecto antibacteriano del EK frente a Escherichia coli y Salmonella typhimu- rium.}

La evaluación se procedió con la siembra de bacterias 
(Escherichia coli y Salmonella typhimurium) en el agar Müller Hinton a partir de una suspensión bacteriana elaborada con cada una de las bacterias en evaluación y agua destilada, procediendo a realizar la siembra de manera uniforme en toda la placa Petri con el objetivo de tener un crecimiento de bacterias a nivel de toda la placa, en la cual se efectuó la evaluación del efecto antibacteriano, luego se dividió en cuadrantes dichas placas con la siembra efectuada para obtener 4 repeticiones en cada una de las placas en evaluación.

Seguidamente se inserta los discos de sensibilidad humedecido con cada tratamiento respectivo en las placas de cada tratamiento que corresponde, que inmediatamente después de terminado la inserción de discos se llevó a incubar las placas a una temperatura de $37^{\circ} \mathrm{C}$ por un tiempo de 18 a 24 horas, y finalmente se procedió a la lectura de placas sobre el efecto antibacteriano obtenido del EK en cada uno de los tratamientos y repeticiones de cada bacteria evaluada.

\subsection{Diseño experimental}

Se evaluó 6 niveles de concentración de EK (6 tratamientos) y un grupo testigo, cada una con 4 repeticiones, las que se plantearon en un diseño completo al azar (DCA). Cada tratamiento se colocó en una placa Petri, en la que se optó por dividir las placas en cuadrantes para evaluar las 4 repeticiones en la misma placa Petri.

\subsection{Análisis de datos}

Los datos obtenidos fueron procesados en el análisis de varianza, y analizados con la prueba de Tukey con un nivel de significancia del 0.05 para determinar las diferencias entre tratamientos.

\section{RESULTADOS}

\section{Figura 1}

Crecimiento del halo de inhibición en $\mathrm{mm}$ frente a Escherichia coli.

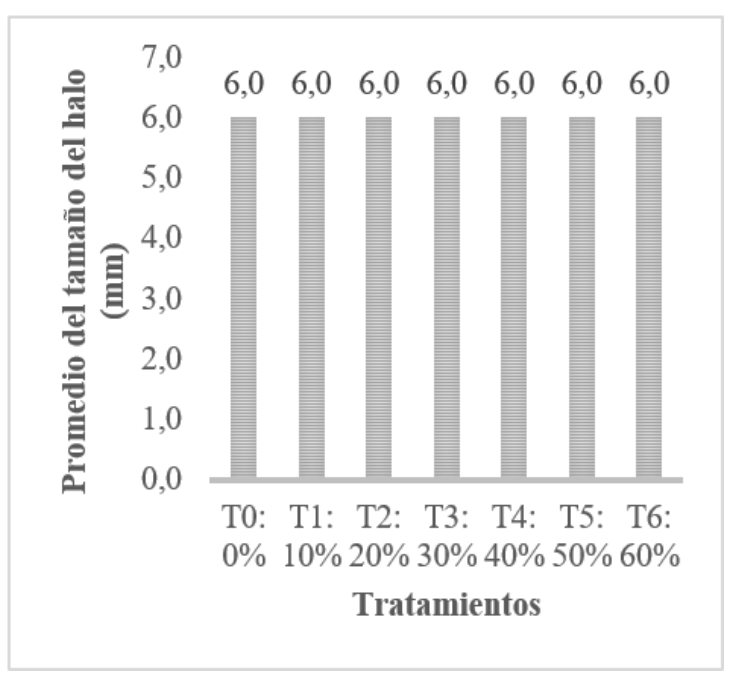

En la figura 1 se observa la homogeneidad en el crecimiento del halo de inhibición (6 $\mathrm{mm}$ ), evidenciando que el EK no presenta efectos antibacterianos contra Escherichia coli con los tratamientos evaluados.

\section{Figura 2}

Crecimiento del halo de inhibición en $\mathrm{mm}$ frente a Salmonella typhimurium.

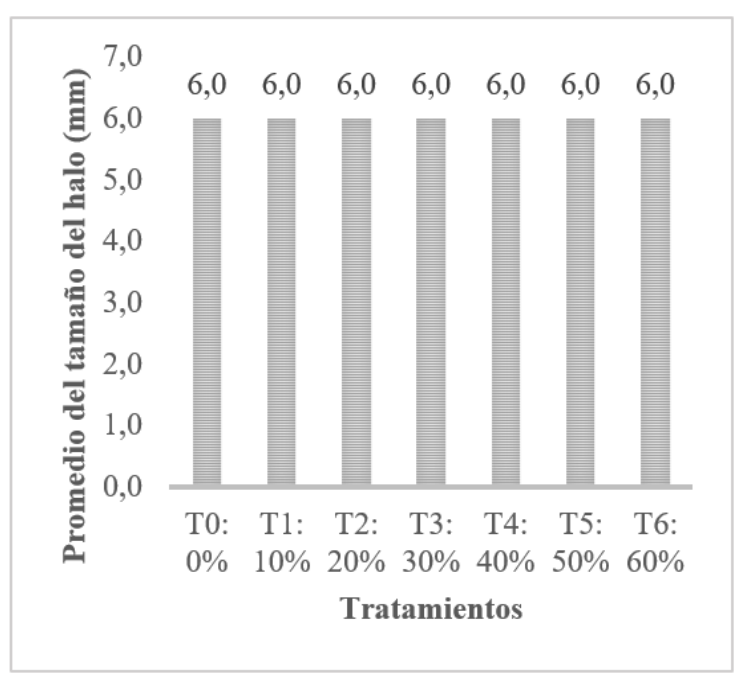

Así mismo en la figura 2 se observa una homogeneidad en el tamaño de crecimiento del halo de inhibición $(6 \mathrm{~mm})$ evidenciando que el EK no presenta efectos antibacterianos contra Salmonella typhimurium con los tratamientos evaluados.

\section{DISCUSIÓN}

Los resultados de la investigación demuestran que el EK (Zingiber officinale) no presenta ningún efecto antibacteriano frente a las bacterias de Escherichia coli y Salmonella typhimurium de los cerdos, cuyas medidas sobre el crecimiento del halo de inhibición es nula, obteniendo tan solo la medida del tamaño del disco de sensibilidad $(6 \mathrm{~mm})$ utilizado para las evaluaciones. Bernal y Guzman (1984) indican que la toma de medidas de los halos de inhibición se realiza sin excluir el tamaño del disco de sensibilidad, lo que significa que una lectura de $6 \mathrm{~mm}$ indica que no existe zona de inhibición.

Se puede observar en las figuras la homogeneidad de datos con un crecimiento nulo de halo de inhibición en las evaluaciones, los cuales nos indican que los resultados de la aplicación del EK en diferentes concentraciones a las bacterias de Escherichia coli y Salmonella typhimurium son iguales a los que obtuvieron Nahuis y Enciso (2018), cuyas evaluaciones se dieron en 3 concentraciones, de las cuales al $50 \%$ y $100 \%$ fueron $6 \mathrm{~mm}$ (medida del disco de sensibilidad) con la diferencia de tan solo en 
una concentración evaluada por éstos autores que es del $25 \%$, en la cual obtuvieron un crecimiento de 10 $\mathrm{mm}$, para el caso de la Escherichia coli.

Así mismo Rengifo (2018) reporta datos de su investigación evaluando el efecto del Zingiber officinale roscoe "jengibre o kion" utilizando el aceite esencial de la raíz de dicho producto en concentraciones de $100 \%$ y $75 \%$, obteniendo buenos resultados $(21,9 \pm 1,9 \mathrm{~mm}$ y $18,5 \pm 1,1 \mathrm{~mm}$ respectivamente) como antibacteriano frente a Escherichia coli que consideraron a ésta bacteria como sensible a este agente en ambas concentraciones, datos enmarcados a nuestra investigación son bastante diferentes haciendo constar la inferioridad de nuestros resultados.

(Rone et al., 2015) realizaron un estudio en la cual evaluaron la actividad antibacteriana de la raíz de Zingiber officinale Roscoe "jengibre", cuyos resultados obtenidos no se alejan mucho al de los obtenidos en nuestra investigación con similares concentraciones, utilizaron $100 \%, 50 \%, 25 \%$ y $12,5 \%$ en forma de tintura; sin embargo se diferencian un crecimiento de $2 \mathrm{~mm}$ y $4 \mathrm{~mm}$ para Escherichia coli y Salmonella spp respectivamente ya que obtuvieron un crecimiento promedio del halo de inhibición de $8 \mathrm{~mm}$ para Escherichia coli y de 10 mm para Salmonella spp, en cambio los resultados de la presente investigación fueron $6 \mathrm{~mm}$ para ambas bacterias.

Ante el evidente caso del crecimiento nulo del halo de inhibición frente a las bacterias de Escherichia coli y Salmonella typhimurium en nuestra investigación se puede inferir que la ausencia del halo de inhibición se debe a que éstas bacterias presentan resistencia bacteriana frente al EK como nos explican la FDA, 2013; OMS, 2014 y CDC, 2016 que fueron citados por Ríos et al., (2019), refiriendo que la resistencia bacteriana está asociada a enzimas que modifican los grupos amino o hidroxilo de una molécula del antibiótico lo cual lleva a consecuencias como el impedimento de la unión del antibiótico al ribosoma y por lo tanto bloquean su actividad antibacteriana, así mismo describen que el uso excesivo de antibióticos en animales de producción y a la transmisión de elementos genéticos entre poblaciones microbianas de los mataderos son causantes importantes de la inhibición del actuar de los diferentes productos antibacterianos.

Gaspar (2018), evaluó la transferencia in vitro de resistencia antibiótica entre miembros comensales y patogénicos del grupo Enterobacteriaceae en íleo de porcino, el que quedó demostrado que el material genético que concede resistencia es absolutamente transmisible entre cepas de Escherichia coli y Salmonella spp., por lo que resulta notorio que estas bacterias son capaces de intercambiar genes dentro de la micro flora intestinal del cerdo lo que conlleva a impedir y tener resultados efectivos ante muchos tratamientos utilizados como productos antibacterianos; con esto se puede demostrar que los resultados obtenidos por parte de nuestra investigación depende también de muchos factores ajenos a nuestra ejecución, ya que existe la probabilidad de que esto esté relacionado con la mala administración de medicamentos antes de nuestra investigación, así mismo por factores como los mencionados al principio de éste párrafo.

La prueba utilizada en la investigación es difusión en agar, cuya prueba permite obtener resultados generalmente cualitativos, así que es necesario explicar que los resultados no se encuentran en los rangos establecidos para ser considerados como bacterias susceptibles o intermedias pero podemos afirmar que son resistentes frente al EK ya que no muestra crecimiento del halo. (Reyes et al., 2005) nos explica de que la susceptibilidad del microorganismo en evaluación está relacionada con el tamaño de la zona de inhibición en milímetros, cuyos microorganismos con una zona mayor a 30-35 $\mathrm{mm}$ son denominadas susceptibles, una zona que varía entre 20 y $30 \mathrm{~mm}$ son intermedios y con una zona cuyo diámetro es menor a $15-20 \mathrm{~mm}$ son resistentes.

\section{CONCLUSIÓN}

Las bacterias Escherichia coli y Salmonella typhimurium no muestran sensibilidad frente a los componentes del EK, por lo contrario se observa una resistencia bacteriana de éstos en sus diferentes concentraciones evaluadas, obteniendo tan solo promedios del tamaño del disco de sensibilidad utilizado $(6 \mathrm{~mm})$.

\section{REFERENCIAS BIBLIOGRÁFICAS}

Bernal, M. y Guzman, M. (1984). El antibiograma de discos. Normalización de la técnica de KirbyBauer. Biomédica 4(3 y 4), 112-121.

Bustos, P. A. y Segura, C. A. (2005). Incidencia de salmonella (Salmonella ssp) y E. Coli en tres granjas porcicolas ubicadas en los municipios de Fómeque y Sibaté.

Departamento de Salud y Servicios Humanos de Estados Unidos, infoSIDA. (2018). Glosario de infoSIDA: Términos relacionados con el $V I H / S I D A$. 9na edición. New York, Estados Unidos.

Fierro, M., Osorio, C., Fandiño, L. y Rondón, I. (2011). Resistencia Antibiótica en Salmonella entérica serovar Typhimurium aisladas de granjas porcícolas en el 
departamento del Tolima. Orinoquia, vol. 15, núm. 1, pp. 71-78.

Flores, R. (2014). La salmonelosis porcina y su importancia en la cadena de producción. IVIS-SUIS N $111,16-21$

Gaspar, J. (2018). Caracterización genética de cepas de Salmonella entérica aisladas desde planteles porcinos. (Tesis de Grado a Maestro). Santiago, Chile: Universidad de Chile.

Lazo, L. (2010). Comportamiento epidemiológico de la colibacilosis entérica porcina en la provincia de Villa Clara, prototipos, genes de virulencia y resistencia a antibióticos en los aislados de Escherichia coli. (Colibacilosis entérica porcina). Revista de Salud Animal, 30(3), 000-195.

Ñahuis, L. G., y Enciso, N. (2018). Efecto antibacteriano in vitro del extracto etanólico del Zingiber officinale (kion) en cepas de Escherichia coli. (Tesis de titulación). Lima, Perú. Universidad Inca Garcilaso de la Vega. Recuperado de http://repositorio.uigv.edu.pe /handle/20.500.11818/3507

Rengifo, R. F. (2018). Efecto bactericida del aceite esencial de la raiz del Zingiber officinale roscoe sobre Escherichia coli ATCC 25922 comparada con Ciprofloxacino, estudio in vitro. (Tesis de Titulación). Trujillo, Perú: Universidad César Vallejo.

Reyes, F., Palou, E. y López, A. (2005). Métodos de evaluación de la actividad antimicrobiana y de determinación de los componentes químicos de los aceites esenciales. Departamento de Ingeniería Química, Alimentos y Ambiental, Universidad de las Américas Puebla. Ex hacienda Sta. Catarina Mártir S/N, San Andrés Cholula, Puebla. C.P.72810. México.

Ríos, A., Morales-Cauti, S., Vilca, M., Carhuallanqui, A., \& Ramos, D. (2019). Determinación del perfil de resistencia antibiótica de Salmonella enterica aislada de cerdos faenados en un matadero de Lima, Perú. Revista de Investigaciones Veterinarias del Perú, 30(1), 438-445.

Rone A, Heloisa F, Maiza E, Perina S, Aparecida F, Bauad T (2015). Avaliação da Atividade Antibacteriana do Gengibre (Zingiber officinale Roscoe) e do Maracujá Amarelo (Passiflora edulis Sims). Rev Ciênc Farm Básica Apl; 36(1):77-82 ISSN 1808-4532

Torres, M. (1996). Manual práctico de bacteriología médica. Guatemala, Guatemala: Serviprensa C.A.

Zozoranga, R. (2014). Estudio de las aplicaciones terapéuticas del jengibre. (Tesis de titulación). Cuenca, Ecuador: Universidad Católica Cuenca 